American Journal of Applied Sciences 7 (11): 1517-1520, 2010

ISSN 1546-9239

(C) 2010 Science Publications

\title{
Investigating the Effect of Powder Type on Improving the Flow in Pipelines
}

\author{
Hayder A. Abdul Bari, Rosli Bin Mohd Yunus and Tania Suhail Hadi \\ Faculty of Chemical and Natural Resources Engineering, \\ University Malaysia Pahang, Malaysia UMP, Locked Bag 12, 25000, \\ Kuantan, Pahang, Malaysia
}

\begin{abstract}
Problem statement: In the present investigation, three types of powders are chosen to be investigated as drag reducing agent in aqueous media. The effect of powder type effect will be highlighted in the present study. Approach: Three types of powders were select to be investigating in the present study, which are the sand, aluminum and the coal powders. The reason behind choosing these powders precisely is the difference in its physical properties, especially the density $\left(\rho_{\text {sand }}=1640\right.$, $\rho_{\text {aluminum }}=2700$ and $\rho_{\text {coal }}=1170 \mathrm{~kg} \mathrm{~m}^{-3}$ ). Results: All the experimental study was carried in a build buildup rig that consisted of a closed loop experimental piping system. Three different addition concentrations $(100,300$ and $500 \mathrm{ppm})$ and five different liquid flow rates were investigated. Conclusion: The experimental results showed that, the aluminum powder drag reduction performance was the higher compared the other two powders investigated (sand and the coal), with maximum $\% \mathrm{Dr}$ up to $45 \%$ by the addition of only $400 \mathrm{ppm}$ addition concentration.
\end{abstract}

Key words: Drag reduction, turbulent flow, pumping power saving, portable ultrasonic measurement, Direct Numerical Simulation (DNS), Laser Doppler Velocimetry (LDV), Reynolds number (Re), aqueous media

\section{INTRODUCTION}

Based on results reported by Lumley (1969), the definition of drag reduction is the reduction of skin friction from turbulent flow. Savins (1964) defined drag reduction as the increase in the pumpability of a fluid caused by the addition of small amounts of another substance, such as high molecular weight polymers, to the fluid. Despite disagreements regarding the definition, the main objective of drag reduction is to reduce the fluid mechanical force known as "drag," which is exerted on an engineering system. A reduction in drag will improve the efficiency of the system (Choi et al., 1996)

Toms (1949) observed a striking reduction in turbulent drag in flows of solutions containing high molecular weight polymethyl methacrylate $(5-10 \mathrm{ppm}$ by weight) in monochlorobenzene and aluminum disoaps in hydrocarbon solvents. It is well known that the addition of a small amount of polymer to a turbulent Newtonian fluid can result in drag reduction in a number of flow fields. Due to this knowledge, interest in the drag reduction of flow fluids has increased rapidly.

Although there have been a number of experimental and theoretical studies in this area for almost a half of a century, a generally accepted explanation of the mechanism of additive-induced drag reduction is not available due to the complexity of this phenomenon. The first explanation was provided by Gadd (1971). He claimed that the damping of the turbulence by polymer additives is due to their resistance to elongational strain, which represses shear formation and bursting in the near-wall region. Lumley $(1973 ; 1977)$ suggested that the uncoiling of polymer molecules under a fluctuating shear rate in the buffer region of turbulent flow causes drag reduction and an increase in the extensional viscosity. Bewersdorff and Berman (1988) created a model related to the aforementioned theory. Matthys (1991) pointed out the common origin of extensional viscosity and viscoelasticity, while De Gennes (1990) hypothesized that polymer drag reduction is due to elastic, rather than viscous phenomenon. After an investigation using Direct Numerical Simulation (DNS) and Laser Doppler Velocimetry (LDV), Den Toonder et al. (1997) claimed that viscous anisotropic stresses introduced by the extension of the polymer plays an integral role in the mechanism of drag reduction.

Myska et al. (2001) classified drag reduction additives into three categories: high and low molecular

Corresponding Author: Hayder A., Faculty of Chemical and Natural Resources Engineering, University Malaysia Pahang, Malaysia UMP, Locked Bag 12, 25000, Kuantan, Pahang, Malaysia 
weight polymers, cationic-anionic-zwitterionic surfactants and fibers. The most effective additives are high molecular weight polymers. However, effectiveness in recirculation systems decreases the rate of degradation. As reported by $\mathrm{Yu}$ et al. (2004), surfactant additives also have problems associated with temporary mechanical and thermal degradations. Surfactants have the ability to self-repair after degradation and this can be accomplished on the order of seconds. Although the use of fiber additives as drag reducing agents are limited, a report from Arranaga (1970) showed the potential of these additives, which reduced drag up to $60 \%$ in pipe flows. Myska et al. (2001) stated that research has been conducted to improve the drag reduction and the mechanical stability of drag reducing polymers. Homopolymers, alternating copolymers, graft polymers, polyelectrolytes and polysaccharides from natural and microbial sources are efficient drag reducing agents in water, organic solvents and crude oil (Gyr and Bewersdorff, 1995; Gad-El-Hak, 2000; Mousa and Tiu, 1994; Mohran, 2009).

\section{MATERIALS AND METHODS}

Transported fluid: The transported fluid used in the present investigation was water.

\section{Liquid circulation system and experimental procedure:}

Experimental rig: An experimental rig was built in order to achieve the aims of this experimental study. The main components of the system consisted of horizontal test section and instrumentations. The pipes with $0.0127,0.0254$ and $0.0381 \mathrm{~m}$ inside diameter and the length of $2 \mathrm{~m}$ made from transparent PVC pipe to permit visual observation of flow pattern in the future was used as the test section. Each pipe divided into four pressure testing sections with a distance equal to $0.5 \mathrm{~m}$. The first pressure testing point for each pipe was located about 50 times pipe diameter (50. D) of the testing pipe as shown in Fig. 1. This is to ensure the turbulent flows are fully developed before the testing point. As shown in Fig. 1, the smallest diameter of pipe which is pipe $\mathrm{C}$ are built as an alternative to control the flow in pipe and as a replacement for bypass pipe since bypass pipe was sometime not appropriate during the experimental study due to formation of heavy foam.

Ultraflux portable flow meter Minisonic P: The flow rate of fluid in pipelines was measures by Ultraflux Portable Flow meter Minisonic $\mathrm{P}$ in which this ultrasonic flow measurement was sensitive with small changes in flow rate as low as $0.001 \mathrm{~m} \mathrm{sec}^{-1}$. The purpose of using this exterior portable ultrasonic measurement is to avoid the pressure losses and prevents leaking that may associate with in-line meter installation.

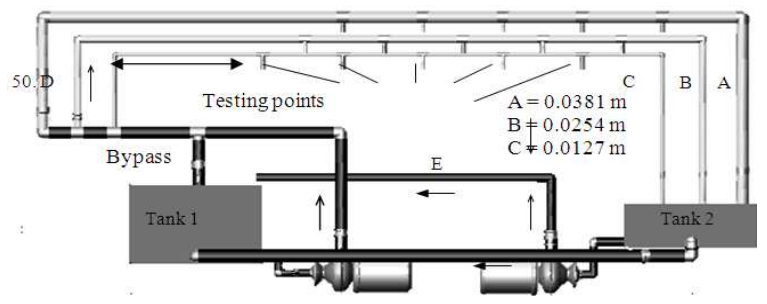

Fig. 1: The experimental rig

Baumer differential pressure gauges: Baumer Differential Pressure Gauge is used to detect the pressure drop in pipelines in which this pressure measurement capable to read the pressure difference in pipelines up to 0.16 bar. In addition, this pressure measurement has high sensitivity and the instrument installation is easy. This pressure gauge was installed in a middle of each testing section in order to make the portable tube easy to remove and connected to the pressure gauge from the testing section during the experiment study.

Experimental calculations: Velocity and Reynolds number calculations: The average Velocity (V) and Reynolds number ( $\mathrm{Re})$ were calculated using the solution volumetric flow rate readings (Q), density $(\rho)$, viscosity $(\mu)$ And pipe Diameter $(D)$, for each run as follows:

$\operatorname{Re}=\frac{\rho \cdot V \cdot D}{\mu}$

Percentage drag reduction calculations: Pressure drop readings through testing sections before and after drag reducer addition, were needed to calculate the percentage drag reduction $\operatorname{Dr}(\%)$ as follows:

$\operatorname{Dr}(\%)=\frac{\Delta \mathrm{P}_{\mathrm{b}}-\Delta \mathrm{P}_{\mathrm{a}}}{\Delta \mathrm{P}_{\mathrm{b}}}$

Where:

$\Delta \mathrm{P}=$ Pressure drop after drag reducer addition

$\Delta \mathrm{P}=$ Pressure drop before drag reducer addition

\section{RESULTS AND DISCUSSION}

Figure 2 show the Effect of particle type on the $\%$ Dr for 500 ppm concentration of sand, coal and aluminum particles suspended in water flowing with pipe diameter of $0.0254 \mathrm{~m} \mathrm{I.D} \mathrm{and} \mathrm{pipe} \mathrm{length} \mathrm{of} 1.5 \mathrm{~m}$. The results of fig. 2 shows that the aluminum powder performance as drag reducing agent is higher 
Am. J. Applied Sci., 7 (11): 1517-1520, 2010

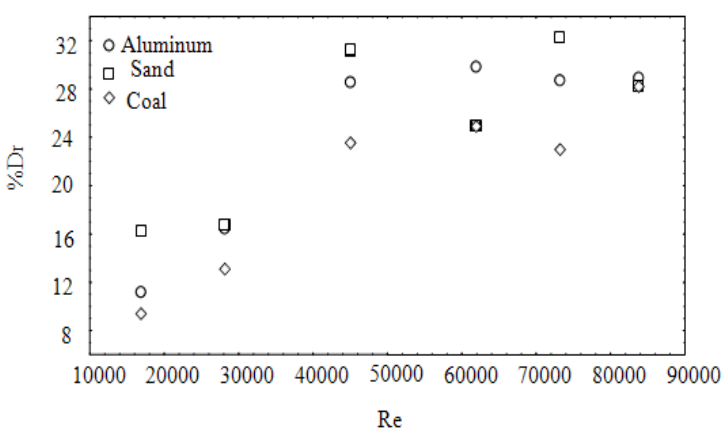

Fig. 2: Effect of particle type on the $\% \mathrm{Dr}$ for $500 \mathrm{ppm}$ concentration of sand, coal and aluminum particles suspended in water flowing with pipe diameter of $0.0254 \mathrm{~m} \mathrm{ID}$ and pipe length of $2.0 \mathrm{~m}$

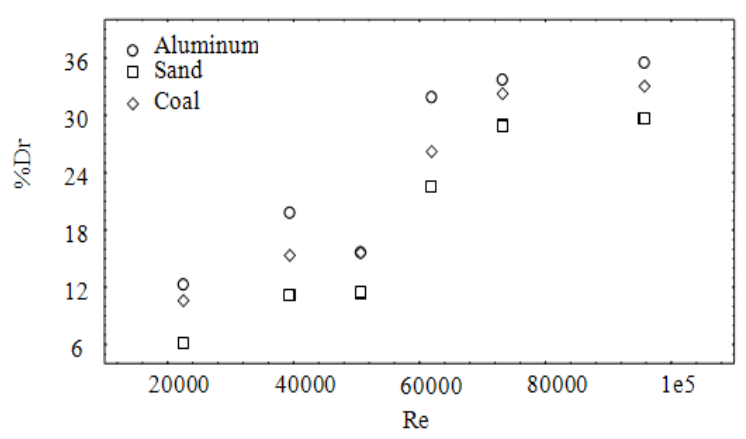

Fig. 3: Effect of particle type on the $\% \mathrm{Dr}$ for $300 \mathrm{ppm}$ concentration of sand, coal and aluminum particles suspended in water flowing with pipe diameter of $0.0125 \mathrm{~m} \mathrm{ID}$ and pipe length of $1.0 \mathrm{~m}$

compared with the coal and the sand powders when $\operatorname{Re}<70,000.00$ while this behavior changes by further increase in the value of $\operatorname{Re}$ and the sand particles perform with higher values of $\% \mathrm{Dr}$. The thing to be observed is that the difference between the aluminum $\% \mathrm{Dr}$ values and those of the sand and coal is higher when $\operatorname{Re}<70,000.00$, while the difference between these point become lower for higher value of $\mathrm{Re}$. The experimental data showed that the difference in the $\%$ Dr was $31 \%$ at $\operatorname{Re}=16900$ and start to narrow down to $8.5 \%$ at $\operatorname{Re}=45058$ and the action was converted after this Re point.

To investigate more on the effect of the particle type on the \%Dr, Fig. 3 and 4 are presented to show the effect of particle type on the \% Dr for different addition concentrations. In addition, the same operating conditions of sand, coal and aluminum particles suspended in water flowing with the same pipe diameter $(0.0125 \mathrm{~m} \mathrm{I.D})$ and pipe length $(1.0 \mathrm{~m})$. From

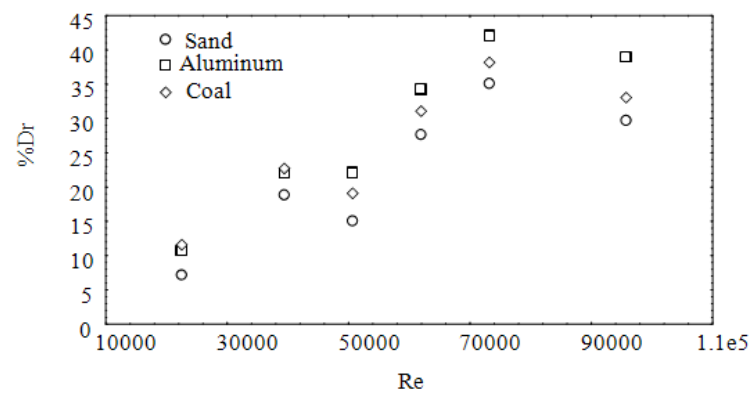

Fig. 4: Effect of particle type on the $\%$ Dr for $500 \mathrm{ppm}$ concentration of sand, coal and aluminum particles suspended in water flowing with pipe diameter of $0.0125 \mathrm{~m} \mathrm{ID}$ and pipe length of $1.0 \mathrm{~m}$

these figures, it can be seen clearly that within the same operating conditions and with different concentrations of the powders, the aluminum powder gave the highest performance in the drag reduction in most of the points presented. While the coal showed also good drag reduction ability and higher values of the \%Dr compared with the sand.

It is beloved that the density of the powder controls in a way or another, the drag reduction ability and performance of the powders. Although that was not completely monitored from the experimental data where some of the results showed that other powders (sand or coal) dominated in some of the experiments but generally it can be concluded that the higher the density of the powder the better the drag reduction ability. That conclusion is limited, because the relation between the density, particle size and the ability of the powder to be suspending in the liquid "buoyancy", is highly influencing the behavior.

From the drag reduction point of view, the drag reduction can occur when the suspended particles interact with the turbulence and the turbulent structures inside the pipe reduces the elasticity of the eddy formed and preventing it from completing its shape. This is because the glob of liquid forming this eddy will have higher apparent density compared with the eddy in the additive-free liquid transportation. Therefore, as the density of the powder interacted with the turbulence is higher, as the density of the eddy formed is higher too and that will lead to breaking down the turbulent structures inside the pipe and increasing the flow.

\section{CONCLUSION}

The aluminum powder showed the higher performance as drag reducing agent in most cases compared with the sand and the coal. The purpose behind that is the wide difference in the apparent 
physical properties of the aluminum powder (especially the density) compared with the other two powders. The higher the density (within certain limits), the better the effect of the suspended solids on suppressing the turbulent eddies inside the main flow, which will lead to a better performance.

\section{REFERENCES}

Arranaga, A.B., 1970. Friction reduction characteristics of fibrous and colloidal substances. Nature, 225: 447-449. DOI: 10.1038/225447a0

Bewersdorff, H.W. and N.S. Berman, 1988. The influence of flow-induced non-Newtonian fluid properties on turbulent drag reduction. Rheol. Acta, 27: 130-136. DOI: 10.1007/BF01331897

Choi, K.S., K.K. Prasad and T.V. Truong, 1996. Emerging Techniques in Drag Reduction. Mechanical Engineering Publications Ltd., London, UK., ISBN: 978-0-85298-917-3, pp: 340.

De Gennes, P.G., 1990. Introduction to Polymer Dynamics. Cambridge University Press, New York, ISBN: 9780511569463, pp: 1-16.

Den Toonder, J.M.J., M.A. Hulsen, G.D.C. Kuiken and F.T.M. Nieuwstadt, 1997. Drag reduction by polymer additives in a turbulent pipe flow: Numerical and laboratory experiments. J. Fluid Mech., 337: 193-231. http://www.mate.tue.nl/mate/showabstract.php/934

Gadd, G.E., 1971. Encyclopedia of Polymer Science and Technology. Wiley-Interscience, New York, pp: 224-253.

Gad-El-Hak, M., 2000. Flow Control, Cambridge University Press, Cambridge, UK., ISBN: 9780521036719, pp: 444.

Gyr, A. and H.W. Bewersdorff, 1995. Drag Reduction of Turbulent Flows by Additives. Kluwer Academic Publishers, Dordrecht, the Netherlands, ISBN-13: 978-0-7923-3485-9, pp: 252.

Lumley, J. L., 1973. Drag reduction in turbulent flow by polymer additives. J. Polym. Sci. Macromol. Rev., 7: 263-290. DOI: 10.1002/pol.1973.230070104
Lumley, J. L., 1977. Drag reduction in two phase and polymer flowsPhys. Fluids, 20: 64-71.

Lumley, J.L., 1969. Drag Reduction by Additives. Ann. Rev. Fluid Mech., 1: 367-384. http://www.annualreviews.org/doi/abs/10.1146/ann urev.f1.01.010169.002055

Matthys, E.F., 1991. Heat transfer, drag reduction and fluid characterization for turbulent flow of polymer solutions: recent results and research needs. J. NonNewtonian. Fluid Mech., 38: 313-342. DOI: 10.1016/0377-0257(91)83010-2

Mohran, H.S., 2009. An electrochemical investigation of the redox properties of murexide in aqueous and non-aqueous media. Am. J. Applied Sci., 6: 964969. DOI: 10.3844/ajassp.2009.964.969

Mousa, T. and C. Tiu, 1994. Factors affecting polymer degradation in turbulent pipe flow. Chem. Eng. Sci., 49: 1681-1692. Doi: 10.1016/00092509(93)E0029-C

Myska, J., Z. Lin, P. Stepanek and J.L. Zakin, 2001. Influence of salts on dynamic properties of drag reducing surfactants. J. Non-Newtonian Fluid Mech., 97: 251-266. Doi: 10.1016/S03770257(01)00097-0

Savins, J.G., 1964. Drag reduction characteristics of solutions of macromolecules in turbulent pipe flow. Soc. Pet. Eng. J., 4: 203-214. http://www.onepetro.org/mslib/servlet/onepetropre view? $\mathrm{id}=00000867 \&$ soc $=$ SPE

Toms, B.A., 1949. Observation on the flow of linear polymer solutions through straight tubes at large Reynolds numbers. Proceeding of the International Rheological Congress 2, Holland, pp: 135-141.

Yu, B., F. Li and Y. Kawaguchi, 2004. Numerical and experimental investigation of turbulent characteristics in a drag-reducing flow with surfactant additives. Int. J. Heat Fluid Flow, 25: 961-974. DOI: 10.1016/J.IJHEATFLUIDFLOW.2004.02.029 